\title{
A rare case of thoracic myelocystocele associated with type 1 split cord malformation with low lying tethered cord, dorsal syrinx and sacral agenesis: Pentad finding
}

\author{
Dipanker Singh Mankotia, Guru Dutta Satyarthee, Bhawani Shankar Sharma \\ Department of Neurosurgery, All India Institute of Medical Sciences, New Delhi, India
}

\section{ABSTRACT}

Myelocystocele is a rare form of spinal dysraphism. Thoracic myelocystocele is still rarer. The occurrence of thoracic myelocystocele associated with type-1 split cord malformation, low lying tethered cord, dorsal syrinx and spina bifida is extremely rare. Clinical presentation of such a rare case and an early surgical management is discussed briefly.

Key words: Low lying tethered cord, spinal dysraphism, split cord malformation, syringomyelia, thoracic myelocystocele

\section{Introduction}

The term myelocystocele was coined by Lassman et al..$^{[1]}$ to describe the severe form of spina bifida cystica associated with hydromyelia in the form of extensive dilatation of the central canal, which may cause cyst projecting through the lamina defect and may occupy the major portion of thecal sac. Myelocystoceles are usually considered rare lesions. ${ }^{[1,2]}$ Terminal myelocystoceles constitute approximately $5 \%$ of skin-covered lumbosacral masses. ${ }^{[2]}$ Dorsal myelocystocele with associated split cord and low lying cord is extremely rare. Rossi et al. ${ }^{[2]}$ described non-terminal myelocystocele as a distinct form of closed spinal dysraphism characterized by a skin-covered meningocele, can be two types, former being crossed by a fibro-neurovascular stalk, which extends from the dorsal aspect of the spinal cord to get attached to the dome of the meningocele sac called

\begin{tabular}{|l|l|}
\hline \multicolumn{2}{|c|}{ Access this article online } \\
\hline Quick Response Code: & Website: \\
\hline & www.ruralneuropractice.com \\
\cline { 2 - 2 } & \\
\hline
\end{tabular}

abortive or myelocystocele manqué, and another type containing hydromyelia cavity, which is continuous with the ependymal canal of the spinal cord called complete type.

\section{Case Report}

A 3-year-old child, born of a non-consanguineous marriage admitted in Neurosurgery department AIIMS, New Delhi, with a swelling in thoracic region since birth with mild difficulty in walking and slight weakness of right lower limb. He had good bowel-bladder control and other developmental milestones were normal. On examination a $6 \times 5 \mathrm{~cm}$ swelling was located at the mid-dorsal region [Figure 1]. The swelling was cystic in consistency, partially compressible, transilluminant in nature. There was no discernible cry impulse. Tuft of hair were also noted in the lumbosacral region. He had weakness in right ankle and EHL, power being $4 / 5+$ and normal in rest of muscle groups. He did not have other associated abnormalities. The head circumference was appropriate for age. MRI revealed constellation of extremely rare developmental spinal malformations. A cystic swelling in the dorsal region crossed by fibro-neurovascular stalk suggestive of dorsal myelocystocele with an associated spina bifida at D7-D8 level [Figure 2], syrinx was noted at D6

Address for correspondence:

Dr. Guru Dutta Satyarthee, Department of Neurosurgery, All India Institute of Medical Sciences, New Delhi - 110029 , India.

E-mail: duttaguru2002@yahoo.com 
level, low lying tethered cord with thick filum, cones at L3 level, split cord was noted at D11 level along with sacral agenesis. NCCT dorsal spine identified a posterior bony spur at D11 [Figure 3]. Surprisingly no associated chair malformation or hydrocephalous was seen. All these findings in a single case make it extremely rare and unique. Patient was taken up for elective surgery. Excision with detethering was done. The myelocystocele sac was dissected up to its neck. The first lamina immediately rostral to the defect was

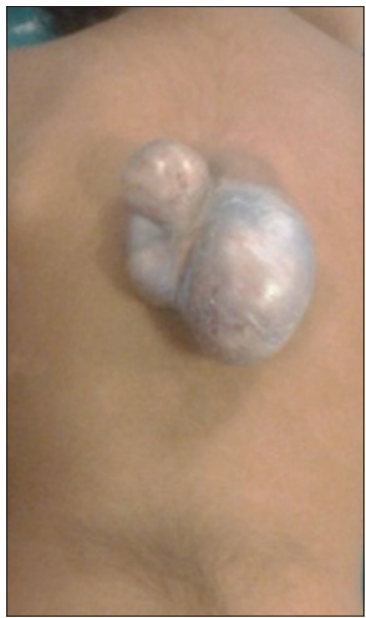

Figure 1: Clinical photograph of the child showing the dorsal myelocystocele

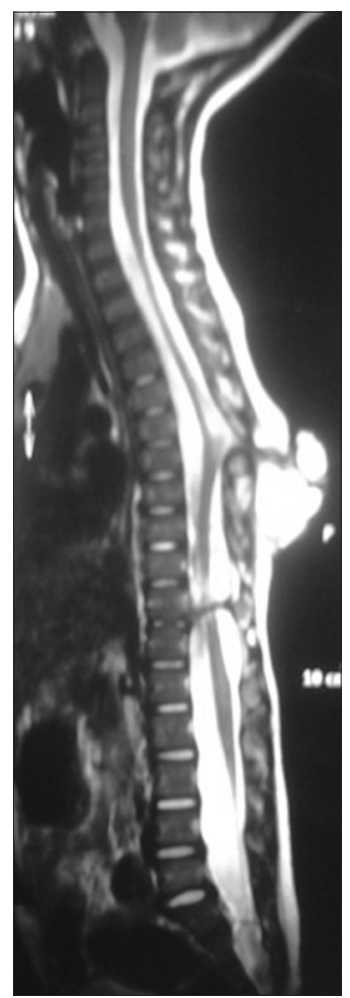

Figure 3: T2W MRI image showing hyperintense myelocystocele sac extending from D7-D10 level, with complete spur at D11 level, also noted is the syrinx at D6 level, low-lying tethered cord at L3 level removed. The dura mater was opened from the normal area and then the incision was extended to the dome of the myelocystocele sac. Arachnoidal adhesions and meningocele manqué were encountered. Nerve roots were seen passing anteriorly from the myelocystocele [Figure 4]. The distended cord was detethered and freed from the sac. D11 bony spur was excised completely [Figure 5]. Fatty filum was identified intraoperatively at L5-S1 level by interlaminar approach which was coagulated and divided. Meticulous primary dural repair was carried out. He had no complications in post-operative period. There was no change in the neurological status following surgery.

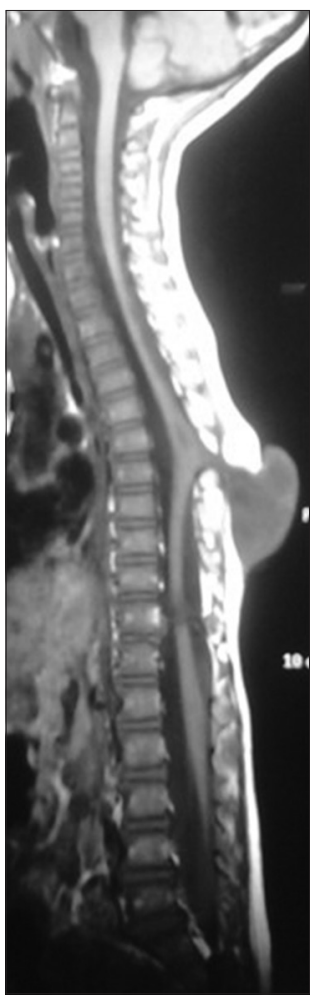

Figure 2: T1W MRI image showing the myelocystocele sac at D7-D10 level

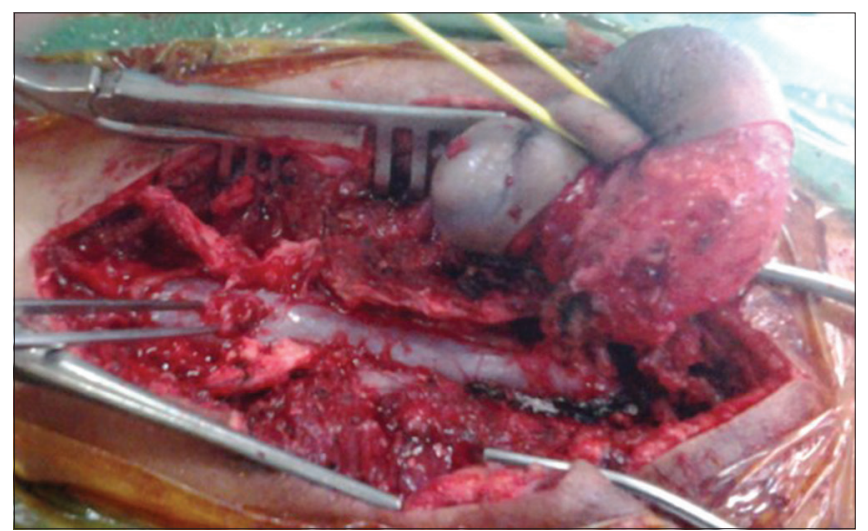

Figure 4: Operative photograph showing the nicely dissected myelocystocele sac and the bony spur 


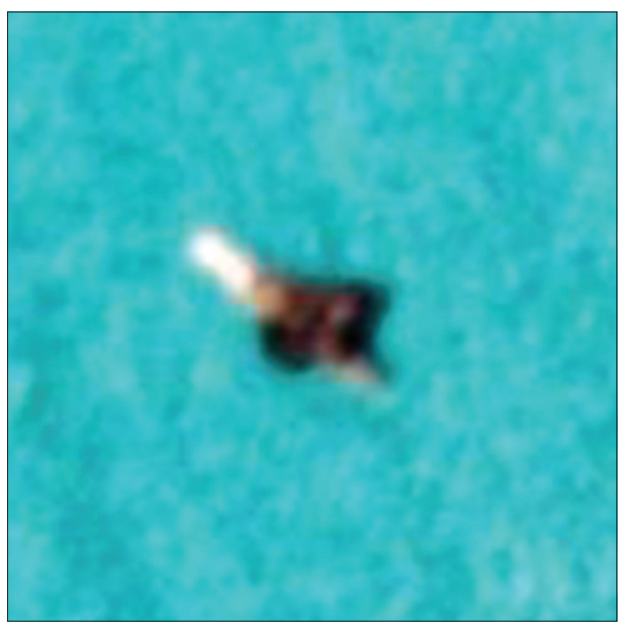

Figure 5: Operative photograph of the bony spur

\section{Discussion}

Neural tube defects are congenital development anomaly of central nervous system. The open type caused by primary neurulation failure leads to exposed neural tissue with discharge of cerebrospinal fluid, while another closed variety is due to faulty secondary neurulation and neural tissue being not exposed. ${ }^{[1]} \mathrm{An}$ anterior neuropore and posterior used to close in last, so these sites remain most vulnerable for congenital defect. A divergent view exists regarding neural tube defects etiogenesis and two common theories have been postulated. The first being orderly closure theory, which is widely accepted. Multiple neural tube defect closure theory is postulated by Van Allen et al. In 1993, described five sites of initiation of neural tube closure and these defects are likely to occur at the collision sites of neural tube closure. ${ }^{[3]}$ Multiple neural defects can have spectrum of associated combination of lesion being simultaneous occurrence of two or more meningomyelocele, or meningocele in combination with encephaloceles or even triple meningoceles, can spread along entire neuraxis, however, such a occurrence along the entire vertebral axis is extremely rare and reported in the form of isolated case reports. ${ }^{[4]}$ Myelocystoceles are usually considered rare lesions ${ }^{[1,2]}$ It can be terminal or non-terminal, former being more common. ${ }^{[3,5]}$ Exact incidence of dorsal myelocystocele is not known ${ }^{[4,6]}$ Rossi et al. ${ }^{[2]}$ classified non-terminal myelocystocele into two variety abortive and complete type. Sim ${ }^{[7]}$ described non-terminal myelocystocele as a very rare type of closed spinal dysraphism characterized by a skin-covered mass in the midline posteriorly, a narrow posterior spina bifida, a CSF-filled cyst, an expanded dural sheath meningocele, and varying amounts of dorsal fat that are continuous with the subcutaneous fat of the back and skin. The clinical features of nonterminal myelocystocele are highly variable. ${ }^{[3,5,6,6,8]}$ Rossi et al. ${ }^{[3]}$ observed no neurological deficits in their six cases of study at admission, while Steenbok and Cochrane noted neurological deficits in two out of three cases having myelocystocele in series of patients having cardiothoracic midline cutaneous mass lesions. ${ }^{[9]}$ Magnetic resonance imaging (MRI) remains the modality of choice to identify myelocystocele and to identify the associated anomalies split cord malformations, tethering, and syringomyelia and Chiari malformations.${ }^{[8]}$ However, computer tomography (CT) scan with bone window helps in better delineation of bony spur. Surgery remains the mainstay of management. Surgical exploration of these lesions aimed at preventing rupture, infection, providing good cosmesis and detethering of cord. ${ }^{[8]}$ However, management includes surgical dethering with careful intradural dissection to avoid fresh neurological deficit and meticulous dural and wound closure. After laminectomy and dural opening, repair of myelocystocele and complete removal of bony spur and detethering are very important. In the current case, thickened filum terminale was divided using separate small incision at L5-S1 level with interlaminar approach to provide complete detethering of cord. Non-terminal myelocystocele may carry better outcome than terminal variety. Muthukumar ${ }^{[10]}$ after comparing the outcome in terminal and non-terminal myelocystocele, concluded a favorable outcome for non-terminal variant. Further, Gupta and Mahapatra ${ }^{[8]}$ analyzed 17 terminal myelocystocele cases, out of which varying degrees of neurological deficits were observed in cases, including two paraplegia with further supporting relatively poor outcome for non-terminal variant.

\section{Conclusion}

High degree of clinical suspicion and neuroimaging like, X-ray and MRI to evaluate spine to exclude other associated lesion. Dorsal myelocystocele associated with type-1 split cord malformation with thickened filum terminale can be managed surgically by two separate incisions at a single stage procedure with good neurological outcome.

\section{References}

1. Lassman LP, James CC, Foster JB. Hydromyelia. J Neurol Sci 1968;7:149-55.

2. McLone DG, Naidich TP. Terminal myelocystocele. Neurosurgery 1985;16:36-43.

3. Rossi A, Piatelli G, Gandolfo C, Pavanello M, Hoffmann C, Van Goethem JW, et al. Spectrum of nonterminal myelocystoceles. Neurosurgery 2006;58:509-15. 
4. Arts MP, de Jong TH. Thoracic meningocele, meningomyelocele or myelocystocele? Diagnostic difficulties, consequent implications and treatment. Pediatr Neurosurg 2004;40:75-9.

5. Rossi A, Biancheri R, Cama A, Piatelli G, Ravegnani M, Tortori-Donati P. Imaging in spine and spinal cord malformations. Eur J Radiol 2004;50:177-200.

6. Steinbok P, Cochrane DD. The nature of congenital posterior cervical or cervicothoracic midline cutaneous mass lesions. Report of eight cases. J Neurosurg 1991;75:206-12.

7. Sim KB, Wang KC, Cho BK. Terminal myelocystocele-a case report. J Korean Med Sci 1996;11:197-202.

8. Gupta DK, Mahapatra AK. Terminal myelocystoceles: A series of
17 cases. J Neurosurg 2005;103(Suppl 4):344-52.

9. Steinbok P, Cochrane DD. Cervical meningoceles and myelocystoceles: A unifying hypothesis. Pediatr Neurosurg 1995;23:317-22.

10. Muthukumar N. Terminal and nonterminal myelocystoceles. J Neurosurg 2007;107(Suppl 2):87-97.

How to cite this article: Mankotia DS, Satyarthee GD, Sharma BS. A rare case of thoracic myelocystocele associated with type 1 split cord malformation with low lying tethered cord, dorsal syrinx and sacral agenesis: Pentad finding. J Neurosci Rural Pract 2015;6:87-90.

Source of Support: Nil. Conflict of Interest: None declared. 